\title{
Oxidation of Single-Walled Carbon Nanotubes under Controlled Chemical Conditions
}

\author{
Arthur B. Porto, ${ }^{a}$ Glaura G. Silva, ${ }^{b}$ Hélio F. dos Santos ${ }^{a}$ and Luiz F. C. de Oliveira ${ }^{*, a}$ \\ ${ }^{a}$ Núcleo de Espectroscopia e Estrutura Molecular, Departamento de Química, Instituto de Ciências Exatas, \\ Universidade Federal de Juiz de Fora, 36036-900 Juiz de Fora-MG, Brazil \\ ${ }^{b}$ Departamento de Química, Instituto de Ciências Exatas, Universidade Federal de Minas Gerais, \\ Pampulha, 31270-901 Belo Horizonte-MG, Brazil
}

\begin{abstract}
Single-walled carbon nanotubes are oxidized in the presence of $\mathrm{H}_{2} \mathrm{SO}_{4} / \mathrm{HNO}_{3}$ mixtures containing distinct concentrations of the nitronium ion, $\left[\mathrm{NO}_{2}^{+}\right]$. The spectroscopic analyses of the final samples suggest a higher structural disorder in the oxidized systems with increasing $\left[\mathrm{NO}_{2}{ }^{+}\right]$. This is due to a considerable oxygen amount on the tube surface, reaching up to $30 \%$, depending on the reaction time and $\left[\mathrm{NO}_{2}^{+}\right]$. Interestingly, if long reaction time is considered, the oxygen amount on the tube surface is maximum for low $\left[\mathrm{NO}_{2}^{+}\right]$and reduces slightly for larger $\left[\mathrm{NO}_{2}{ }^{+}\right]$. On the other hand, the oxidation process occurs gradually at $4 \mathrm{~h}$, allowing a fine control of the oxidation process. Therefore, if fine tuning of the oxidation degree is desirable, the reaction must be conducted during short time $(4 \mathrm{~h})$ using increasing $\left[\mathrm{NO}_{2}{ }^{+}\right]$as those obtained from $2: 1,2.5: 1$ and $3: 1 \mathrm{H}_{2} \mathrm{SO}_{4} / \mathrm{HNO}_{3}$ acid mixtures to produce increasing content of functionalization.
\end{abstract}

Keywords: SWCNT, acid mixture, $\mathrm{H}_{2} \mathrm{SO}_{4} / \mathrm{HNO}_{3}$, Raman, DFT

\section{Introduction}

The potential applications of carbon nanotubes (CNTs) are currently well-recognized due to their unique physical and chemical properties..$^{1-3}$ Nonetheless, the practical use of CNTs has some barriers since, without prior treatment, they are chemically inert and present low dispersion in most common solvents. ${ }^{4-6}$ Moreover, CNT samples contain amorphous carbon, metallic catalysts, nanotubes with different diameters, and other impurities. Therefore, synthesized CNT samples need chemical treatment to remove the side products and improve reactivity and dispersion. ${ }^{6}$ Often, the chemical treatment consists, at least in a first stage, of oxidation reactions creating different functional groups on the tube surface, such as $-\mathrm{OH},-\mathrm{COH}$ and $-\mathrm{COOH} .{ }^{7}$ This can be done either with $\mathrm{O}_{2}$ at high temperature to remove amorphous carbon or by oxidizing solutions containing $\mathrm{H}_{2} \mathrm{O}_{2}$ or $\mathrm{KMnO}_{4}{ }^{8,9}$ The most common process consists in using concentrated acid solutions of $\mathrm{HCl}, \mathrm{H}_{2} \mathrm{SO}_{4}, \mathrm{HNO}_{3}$ or a mixture of $\mathrm{H}_{2} \mathrm{SO}_{4} / \mathrm{HNO}_{3}$, which remove most of the amorphous carbon and metallic catalysts. ${ }^{10-12}$ This also promotes chemical modification of the CNT surface with the creation of several oxygen functional groups and topological defects.

*e-mail: luiz.oliveira@ufjf.edu.br
Devaux et al. ${ }^{12}$ explored the covalent functionalization of single-walled carbon nanotubes (SWCNTs) through mild oxidation in an acid solution of $\mathrm{H}_{2} \mathrm{SO}_{4}$ and $\mathrm{HNO}_{3}$. The products were analyzed by Raman and infrared spectroscopies. The Raman spectra showed a decrease of the D band intensity after acid treatment, suggesting the removal of impurities without considerable damage to the SWCNT structure. The infrared spectra showed absorption bands due to the oxygen groups $-\mathrm{OH}$ and $-\mathrm{C}=\mathrm{O}$ of carboxylic acid and quinone after the oxidation process.

Regarding oxidation with concentrated acids, a mixture of $\mathrm{H}_{2} \mathrm{SO}_{4} / \mathrm{HNO}_{3}$ is often used. It can effectively remove the impurities and promote significant functionalization of the CNT surface. This mixture produces the nitronium ion $\left(\mathrm{NO}_{2}^{+}\right)$in situ according to the reaction $2 \mathrm{H}_{2} \mathrm{SO}_{4}+\mathrm{HNO}_{3} \rightarrow \mathrm{NO}_{2}{ }^{+}+\mathrm{H}_{3} \mathrm{O}^{+}+2 \mathrm{HSO}_{4}^{-}$. This is considered one of the main active species responsible for oxygen transfer to the CNT surface. The nitronium ion is a strong electrophilic species and interacts with the electron-rich CNT surface. This has been proven in the CNT oxidation by nitronium ion solution from $\mathrm{NO}_{2} \mathrm{SbF}_{6}$ and $\mathrm{NO}_{2} \mathrm{BF}_{4}$ salts. ${ }^{13,14}$

Da Silva et al. ${ }^{15}$ proposed an oxidation mechanism of SWCNT in acid solution using computational approaches. They used ab initio calculations with periodic boundary conditions to investigate the interaction between the 
species $\mathrm{NO}_{2}{ }^{+}+\mathrm{H}_{2} \mathrm{O}+\mathrm{NO}_{3}{ }^{-}$and an armchair $(6,6) \mathrm{SWCNT}$. The results suggested an oxygen transfer from $\mathrm{NO}_{2}{ }^{+}$to the SWCNT with formation of carbonyl groups without changing the metallic nature of the SWCNT. In our previous work, ${ }^{16}$ the interaction between $\mathrm{NO}_{2}{ }^{+}$and an SWCNT was investigated using density functional theory (DFT). Three models for an armchair $(6,6)$ SWCNT were used as follows: one pristine form and two structures with topological defects. The oxidation pathway was described, including the energy barriers for oxygen transfer from $\mathrm{NO}_{2}^{+}$ to SWCNT and the formation of the oxygen-containing functional groups epoxide, ether and carbonyl.

Since the nitronium ion can be obtained from the acid mixtures $\mathrm{H}_{2} \mathrm{SO}_{4} / \mathrm{HNO}_{3}$, its concentration can be varied by acid proportions. Edwards et al. ${ }^{17}$ studied the equilibrium in acid mixture with different proportions of $\mathrm{H}_{2} \mathrm{SO}_{4}, \mathrm{HNO}_{3}$ and $\mathrm{H}_{2} \mathrm{O}$. They used a mixture of $\mathrm{H}_{2} \mathrm{SO}_{4}(98 \%), \mathrm{HNO}_{3}(95 \%)$ and water to create solutions with different stoichiometries of the species and then quantified the nitronium ion concentration. The results showed that increasing the percentage of water in solution decreases the nitronium ion concentration. Moreover, increasing the proportion of sulfuric acid increases the nitronium ion concentration.

In the oxidation of CNTs, it is common to indicate the acid proportions in volume ( $\mathrm{v} / \mathrm{v})$ instead of concentration of $\mathrm{NO}_{2}{ }^{+}$, therefore, it would be worthwhile to establish such a correlation. Gong et al. ${ }^{18}$ performed the oxidation of multiwalled carbon nanotubes (MWCNT) using pure nitric acid and $\mathrm{H}_{2} \mathrm{SO}_{4} / \mathrm{HNO}_{3}$ mixtures in different v/v proportions: 1:1, 2:1, 3:1, 4:1 and 5:1 $\left(\mathrm{H}_{2} \mathrm{SO}_{4}: \mathrm{HNO}_{3}\right)$. They observed that the $-\mathrm{COOH}$ concentration increased from $1: 1$ to $3: 1$ and then slightly decreased. The available experimental studies suggest that different mixtures yield distinct concentrations of $\mathrm{NO}_{2}{ }^{+}$and, consequently, might control the CNT oxidation. However, they do not establish quantitative relationships between $\mathrm{H}_{2} \mathrm{SO}_{4} / \mathrm{HNO}_{3}$ mixtures, $\mathrm{NO}_{2}{ }^{+}$ concentration and oxidation degree. This is the main goal of the present study that intends to understand and explore the reaction between $\mathrm{CNT}$ and $\mathrm{NO}_{2}{ }^{+}$under chemical control of the oxidizer concentration. Analysis of the $\mathrm{H}_{2} \mathrm{SO}_{4} / \mathrm{HNO}_{3}$ acid mixture in different $\mathrm{v} / \mathrm{v}$ proportions, $1: 1,2: 1,2.5: 1$, $3: 1,4: 1,5: 1,6: 1,7: 1$ and $8: 1$, was performed with the aim of quantifying the free $\mathrm{NO}_{2}{ }^{+}$concentration available in solution. This was done by using a standard solution of $\mathrm{NO}_{2} \mathrm{BF}_{4}$ in $\mathrm{H}_{2} \mathrm{SO}_{4}$ and the $\mathrm{v}\left(\mathrm{NO}_{2}^{+}\right)$Raman band intensity to monitor the ion concentration. A calibration curve could be obtained by plotting the intensity of the $v\left(\mathrm{NO}_{2}{ }^{+}\right)$band against $\left[\mathrm{NO}_{2}{ }^{+}\right]$. Furthermore, three $\mathrm{H}_{2} \mathrm{SO}_{4}: \mathrm{HNO}_{3}$ solutions with proportions of (v/v) 2:1, 2.5:1 and 3:1 were used to oxidize the SWCNT samples and the products were analyzed by Raman spectroscopy, thermogravimetric analysis (TGA) and energy dispersive spectroscopy (EDS) in addition to DFT calculations.

\section{Experimental}

\section{Samples}

Sulfuric acid (95-99\%) and nitric acid (65\%) were both purchased from Vetec, and nitronium tetrafluoroborate $\left(\mathrm{NO}_{2} \mathrm{BF}_{4}\right)(\geq 95 \%)$ was purchased from Sigma-Aldrich. The SWCNT sample used in this study was purchased from Sigma-Aldrich and prepared by the CoMoCat ${ }^{\mathrm{TM}}$ (catalytic chemical vapor deposition (CVD) method). According to the manufacturer, the sample has composition of carbon $\geq 95 \%$, and $\geq 93 \%$ as SWCNTs with diameters in the range $0.7-0.9 \mathrm{~nm}$.

\section{Calibration plot}

The standard solutions of nitronium ion were prepared in duplicate by dissolving the $\mathrm{NO}_{2} \mathrm{BF}_{4}$ salt in sulfuric acid (95-99\%) to obtain a $2.0 \mathrm{M}$ solution. Successive dilutions were performed to prepare 1.8, 1.6, 1.4, 1.2, 1.0, 0.8, 0.6, 0.4 and $0.2 \mathrm{M}$ solutions. The concentration of nitronium ion was monitored by the area of the band assigned to $v\left(\mathrm{NO}_{2}{ }^{+}\right)$ at ca. $1400 \mathrm{~cm}^{-1}$ in the Raman spectrum.

\section{Acid mixtures}

The acid mixtures were prepared with fixed volume of $10 \mathrm{~mL}$ in different $\mathrm{H}_{2} \mathrm{SO}_{4} / \mathrm{HNO}_{3}$ proportions (v/v): $1: 1$, $2: 1,2.5: 1,3: 1,4: 1,5: 1,6: 1,7: 1$ and 8:1. The mixtures were prepared at low temperature in an ice bath to minimize the formation of nitrosylsulfuric acid and to prevent the loss of nitric acid. The Raman spectra were obtained immediately.

\section{SWCNT oxidation}

The oxidation of the SWCNTs was performed through a set of experiments varying the reaction time and the proportion of the acid mixtures. For each experiment, $50 \mathrm{mg}$ of SWCNTs were used with the acid mixtures 2:1, 2.5:1, and $3: 1(\mathrm{v} / \mathrm{v})$ in a total volume of $50 \mathrm{~mL}$ prepared in an ice bath. The reactions were carried out in an ultrasound bath for $1 \mathrm{~h}$ plus 4,8 or $12 \mathrm{~h}$ with magnetic stirring (at room temperature), resulting in three experiments for each acid mixture. After oxidation, the samples were repeatedly centrifuged to separate the solid phase, and the excess acid was removed by washing until achieving a neutral $\mathrm{pH}$. The solid phase was then dried for $48 \mathrm{~h}$ at $130^{\circ} \mathrm{C}$. 


\section{Raman spectroscopy}

Fourier transform Raman spectra were carried out for all samples used for the calibration plot and the acid treatment using a Bruker RFS 100 instrument, an neodymium-doped yttrium aluminium garnet (Nd:YAG) laser operating at $1064 \mathrm{~nm}$ and a liquid nitrogen cooled $\mathrm{Ge}$ detector. The system had $4 \mathrm{~cm}^{-1}$ of spectral resolution for 256 scans using a laser power of $200 \mathrm{~mW}$ at the sample. The SWCNT samples were analyzed in a dispersive Raman Bruker SENTERA with a laser operating at $633 \mathrm{~nm}$ and a charge-coupled device (CCD) detector with 3-5 $\mathrm{cm}^{-1}$ of spectral resolution and 10 co-addictions of $10 \mathrm{~s}$ using a laser power of $2 \mathrm{~mW}$ at the sample. All spectra were obtained at least twice to guarantee the position and intensity of each observed band in the spectra.

\section{Scanning electron microscopy (SEM)-EDS analysis}

SEM images were obtained in a tabletop Hitachi TM 3000 instrument featuring improved electron optics, high magnification, and built-in image processing to further enhance image quality and resolution at lower accelerating voltage. The system was operated at 5 or $15 \mathrm{kV}$ with magnification from 15 to $30,000 \times$, without any sample preparation. An energy dispersive X-ray spectrophotometer Quantax 70 EDX from Bruker was also used for light element detection from boron upwards, with available linescan, mapping and multiple point analysis at the sample.

\section{Thermogravimetric analysis}

The thermogravimetric analysis was performed using a Shimadzu DTG60 with a heating rate of $10^{\circ} \mathrm{C} \mathrm{min}{ }^{-1}$ under synthetic air atmosphere from 25 to $850{ }^{\circ} \mathrm{C}$.

\section{DFT calculations}

Some CNT oxidized structures were modelled using a $(6,5)$ SWCNT with molecular formula $\mathrm{C}_{180} \mathrm{H}_{22} \mathrm{O}_{22}$. The models have nominal length of $22 \AA$ and diameter of $0.75 \mathrm{~nm}$. Six SWCNT structures were constructed: pristine (P), without topological defects; an SWCNT with a Stone-Wales defect (SW); and four SWCNTs with SW defects oxidized with 1-4 oxygen atoms, called SW-1O, SW-2O, SW-3O and SW-4O, respectively (Figure 1). The geometries and Raman spectra were calculated for all structures in vacuum at the DFT level with the hybrid Becke, three-parameter, Lee-Yang-Parr (B3LYP) ${ }^{19}$ functional and 6-31G(d) split-valence basis set. ${ }^{20,21} \mathrm{~A}$
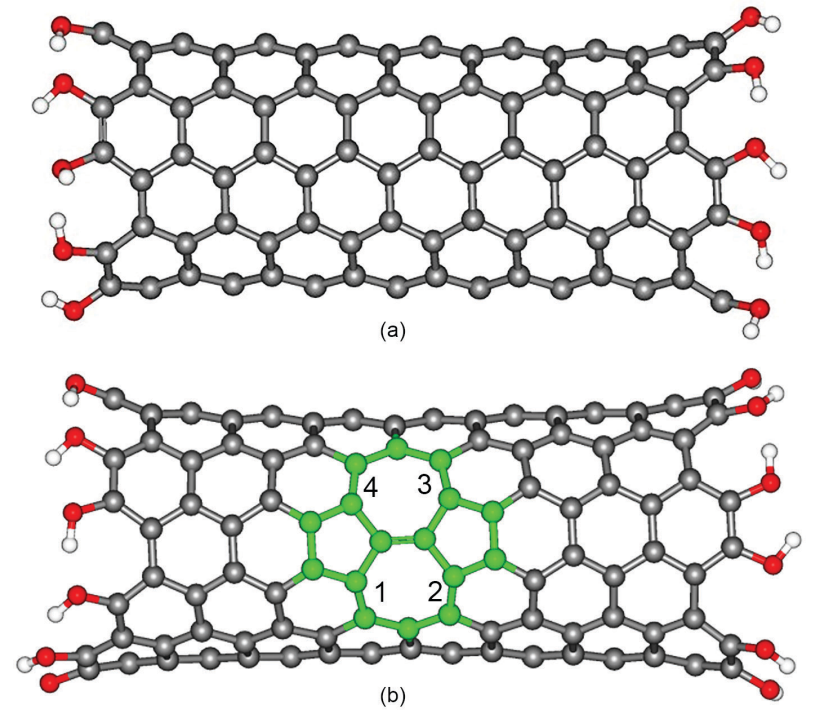

Figure 1. Molecular models for an SWCNT with the molecular formula $\mathrm{C}_{180} \mathrm{H}_{22} \mathrm{O}_{22}$ : (a) pristine (P) and (b) Stone-Wales (SW) defect in green. The carbon atoms indicated by positions 1-4 were substituted by oxygen atoms to create the models named SW-1O, SW-2O, SW-3O and SW-4O.

similar level of theory was used in our previous paper regarding the oxidation of SWCNTs in an acid medium. ${ }^{16}$

\section{Results and Discussion}

Acid mixture equilibrium

The $\mathrm{H}_{2} \mathrm{SO}_{4}: \mathrm{HNO}_{3}$ acid mixture is often used to oxidize CNTs, where the $\mathrm{NO}_{2}{ }^{+}$ion is the main oxidizing species in solution. First, a calibration plot using standard solutions of nitronium ions was constructed. The nitronium ion has a characteristic Raman signal at ca. $1400 \mathrm{~cm}^{-1}$, assigned to $v\left(\mathrm{NO}_{2}^{+}\right)$, that was used to monitor the species concentration in solution. The corresponding band area was integrated and linearly correlated with the concentration of $\mathrm{NO}_{2}{ }^{+}$in solution. The calibration plot is shown in Figure 2 and equation 1.

$\left[\mathrm{NO}_{2}^{+}\right]=(-0.020 \pm 0.009)+(0.120 \pm 0.007) \mathrm{A}_{\mathrm{NO}_{2}^{+}}$; $\mathrm{R}=0.967$

The acid mixture involves many equilibrium processes, and different species are formed from dissociation and reaction between the two acids (equations 2-5).

$$
\begin{aligned}
& \mathrm{H}_{2} \mathrm{SO}_{4}+\mathrm{H}_{2} \mathrm{O} \rightleftarrows \mathrm{HSO}_{4}^{-}+\mathrm{H}_{3} \mathrm{O}^{+} \\
& \mathrm{HSO}_{4}^{-}+\mathrm{H}_{2} \mathrm{O} \rightleftarrows \mathrm{SO}_{4}^{2-}+\mathrm{H}_{3} \mathrm{O}^{+} \\
& \mathrm{HNO}_{3}+\mathrm{H}_{2} \mathrm{O} \rightleftarrows \mathrm{NO}_{3}^{-}+\mathrm{H}_{3} \mathrm{O}^{+} \\
& 2 \mathrm{H}_{2} \mathrm{SO}_{4}+\mathrm{HNO}_{3} \rightleftarrows \mathrm{NO}_{2}^{+}+\mathrm{H}_{3} \mathrm{O}^{+}+2 \mathrm{HSO}_{4}^{-}
\end{aligned}
$$

With the aim of understanding the composition of the acid mixtures, Raman spectroscopy was used to identify the 


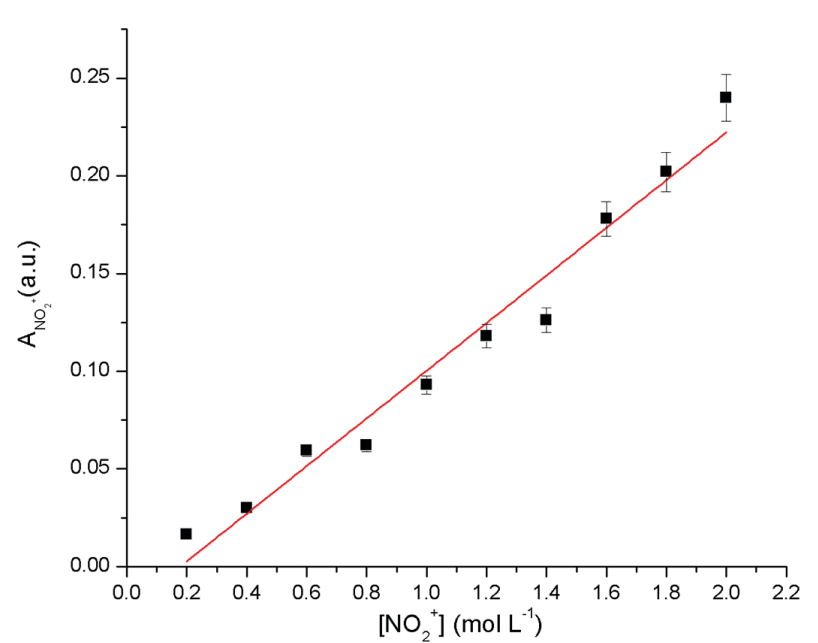

Figure 2. Calibration plot obtained by the area of the vibrational band assigned to the $v\left(\mathrm{NO}_{2}^{+}\right)\left(\right.$at $\left.1400 \mathrm{~cm}^{-1}\right) v s$. nitronium ion concentration in a standard $\mathrm{NO}_{2} \mathrm{BF}_{4}$ solution.

main species. The Raman spectra for the acid mixtures are shown in Figure 3, and the main assignments are presented in Table 1.

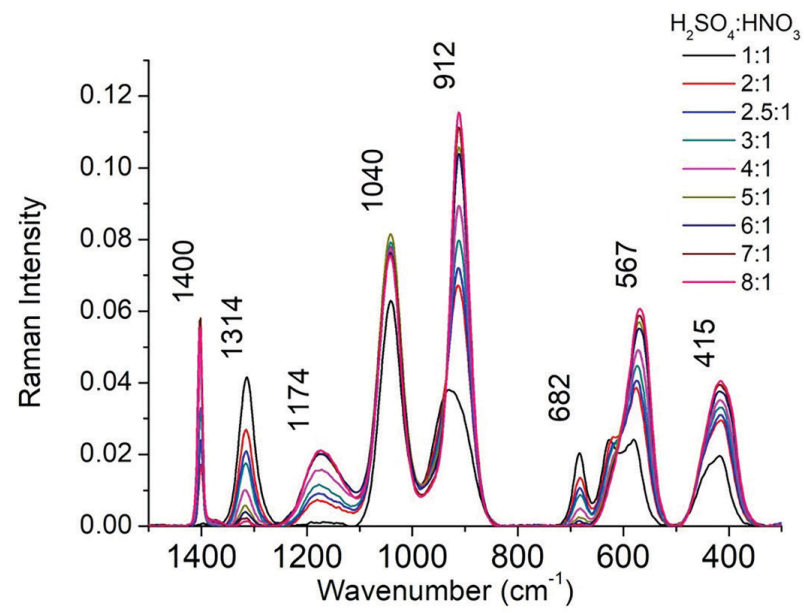

Figure 3. Raman spectra of acid mixtures in different $\mathrm{H}_{2} \mathrm{SO}_{4}: \mathrm{HNO}_{3}$ proportions (v/v): 1:1, 2:1, 2.5:1, 3:1, 4:1, 5:1, 6:1, 7:1 and 8:1.

Table 1. Assignments of the Raman bands of the $\mathrm{H}_{2} \mathrm{SO}_{4}: \mathrm{HNO}_{3}$ acid mixtures

\begin{tabular}{lcc}
\hline Wavenumber $/ \mathrm{cm}^{-1}$ & Species & Assignment \\
\hline $415 \mathrm{~m}$ & $\mathrm{SO}_{4}{ }^{2-}$ & $\delta \mathrm{SO}_{4}$ \\
$567 \mathrm{~m}$ & $\mathrm{HSO}_{4}{ }^{-}+\mathrm{HNO}_{3}$ & $\delta \mathrm{SO}_{2}+\delta \mathrm{N}-\mathrm{O}-\mathrm{H}$ \\
$682 \mathrm{w}$ & $\mathrm{HNO}_{3}$ & $\delta \mathrm{O}-\mathrm{N}-\mathrm{O}+\mathrm{vN}-\mathrm{OH}$ \\
$912 \mathrm{~s}$ & $\mathrm{SO}_{4}^{2-}+\mathrm{HNO}_{3}$ & $v_{\mathrm{s}} \mathrm{SO}_{4}+\mathrm{vN}-\mathrm{OH}$ \\
$1040 \mathrm{~s}$ & $\mathrm{HSO}_{4}^{-}+\mathrm{NO}_{3}{ }^{-}$ & $v_{\mathrm{s}} \mathrm{SO}_{4}+\mathrm{v}_{\mathrm{s}} \mathrm{NO}_{3}$ \\
$1174 \mathrm{w}$ & $\mathrm{H}_{2} \mathrm{SO}_{4}+\mathrm{HSO}_{4}^{-}$ & $\delta \mathrm{SO}-\mathrm{H}$ \\
$1314 \mathrm{~m}$ & $\mathrm{HNO}_{3}$ & $\delta \mathrm{N}-\mathrm{O}-\mathrm{H}$ \\
$1400 \mathrm{~m}$ & $\mathrm{NO}_{2}{ }^{+}$ & $v_{\mathrm{s}} \mathrm{NO}_{2}{ }^{+}$ \\
\hline
\end{tabular}

$\mathrm{m}$ : moderate; w: weak; s: strong; $\delta$ : deformation; $v$ : stretching; $v_{\mathrm{s}}$ : antisymmetric.
The bands due to sulfuric acid and the other species arising from its dissociation increase in intensity with the sulfuric acid proportion, as observed for the bands at 415 , 567,912 and $1174 \mathrm{~cm}^{-1}$. On the other hand, the bands due to nitric acid at 682 and $1314 \mathrm{~cm}^{-1}$ decrease in intensity since the nitric acid was added in smaller volumes than sulfuric acid, and part of this is consumed for nitronium ion formation. The nitronium ion band at $1400 \mathrm{~cm}^{-1}$ does not appear in the 1:1 mixture, indicating that, under this condition, the $\mathrm{NO}_{2}{ }^{+}$ion is not formed in a significant amount. For the other mixtures, the band at $1400 \mathrm{~cm}^{-1}$ is clearly observed. Since the nitronium ion plays a primary role in the CNT oxidation reaction, its quantification in the acid mixtures is important and can be accomplished using Raman spectroscopy with the aid of the calibration curve represented by equation 1 . The results are shown in Table 2, showing the observed $\mathrm{NO}_{2}{ }^{+}$concentration and the initial concentration of $\mathrm{H}_{2} \mathrm{SO}_{4}, \mathrm{HNO}_{3}$ and $\mathrm{H}_{2} \mathrm{O}$ for all mixtures analyzed. Overall, the increasing concentration of $\mathrm{H}_{2} \mathrm{O}$ implies a decrease in $\left[\mathrm{NO}_{2}{ }^{+}\right]$, conversely, the $\left[\mathrm{NO}_{2}{ }^{+}\right]$increases with $\left[\mathrm{H}_{2} \mathrm{SO}_{4}\right]$. These trends are in line with previous work by Edwards et al. ${ }^{17}$ The temperature also influences the equilibria represented in equations 2-5. Edwards et al. ${ }^{17}$ demonstrated that increasing the temperature leads to a decrease in $\left[\mathrm{NO}_{2}{ }^{+}\right]$. Herein, all mixtures were prepared in an ice bath, and the spectroscopic analysis was made at room temperature.

\section{SWCNT oxidation}

To investigate the influence of the nitronium ion concentration and reaction time on the CNT oxidation, we chose the acid mixtures $\left(\mathrm{H}_{2} \mathrm{SO}_{4}: \mathrm{HNO}_{3}, \mathrm{v} / \mathrm{v}\right)$ $2: 1\left(\left[\mathrm{NO}_{2}^{+}\right]=1.40 \mathrm{~mol} \mathrm{~L}^{-1}\right), 2.5: 1\left(\left[\mathrm{NO}_{2}{ }^{+}\right]=1.89 \mathrm{~mol} \mathrm{~L}-1\right)$ and $3: 1\left(\left[\mathrm{NO}_{2}{ }^{+}\right]=2.56 \mathrm{~mol} \mathrm{~L}^{-1}\right)$ and reaction times 4,8 and $12 \mathrm{~h}$ (plus $1 \mathrm{~h}$ of the ultrasound bath) in nine experiments. The Raman spectra of the oxidized samples obtained at room temperature with a $633 \mathrm{~nm}$ excitation laser are shown in Figure 4 in the region between $1800-1200 \mathrm{~cm}^{-1}$ (D/G bands) and Figure 5 in the region between $400-200 \mathrm{~cm}^{-1}$ (radial breathing mode (RBM) bands).

Figure 4 shows the main Raman bands of the CNTs in the $1200-1800 \mathrm{~cm}^{-1}$ range. The intensity of the D band between $1300-1370 \mathrm{~cm}^{-1}$ refers to induced disorder, i.e., a higher oxidation degree corresponds to greater disorder and consequently a more intense $\mathrm{D}$ band. The $\mathrm{G}$ band occurs in the range $1500-1605 \mathrm{~cm}^{-1}$ and is assigned to vibrations of all carbon materials. In SWCNTs, the G band consists of two main components: one peak at high frequency $1590 \mathrm{~cm}^{-1}\left(\mathrm{G}^{+}\right)$associated with vibrations along the nanotube main axis and a second peak observed at low 
Table 2. Molar concentration of $\mathrm{NO}_{2}{ }^{+}$observed in $\mathrm{H}_{2} \mathrm{SO}_{4}: \mathrm{HNO}_{3}$ acid mixtures. The original concentrations of the acids and water are also provided

\begin{tabular}{lcccc}
\hline Proportion $\left(\mathrm{H}_{2} \mathrm{SO}_{4}: \mathrm{HNO}_{3}, \mathrm{v} / \mathrm{v}\right)$ & {$\left[\mathrm{NO}_{2}^{+}\right] /\left(\mathrm{mol} \mathrm{L}^{-1}\right)$} & {$\left[\mathrm{H}_{2} \mathrm{SO}_{4}\right] /\left(\mathrm{mol} \mathrm{L}^{-1}\right)$} & {$\left[\mathrm{HNO}_{3}\right] /\left(\mathrm{mol} \mathrm{L}^{-1}\right)$} & {$\left[\mathrm{H}_{2} \mathrm{O}\right] /\left(\mathrm{mol} \mathrm{L}^{-1}\right)$} \\
\hline $1: 1$ & 0.00 & 8.92 & 4.22 & 11.11 \\
$2: 1$ & 1.40 & 11.95 & 4.77 & 8.28 \\
$2.5: 1$ & 1.89 & 12.80 & 4.10 & 7.52 \\
$3: 1$ & 2.56 & 13.38 & 3.61 & 6.69 \\
$4: 1$ & 3.63 & 14.27 & 2.89 & 6.11 \\
$5: 1$ & 4.48 & 14.80 & 2.46 & 5.62 \\
$6: 1$ & 4.23 & 15.34 & 2.06 & 5.02 \\
$7: 1$ & 4.53 & 15.61 & 1.81 & 4.87 \\
$8: 1$ & 4.33 & 15.87 & 1.60 & 4.61 \\
\hline
\end{tabular}
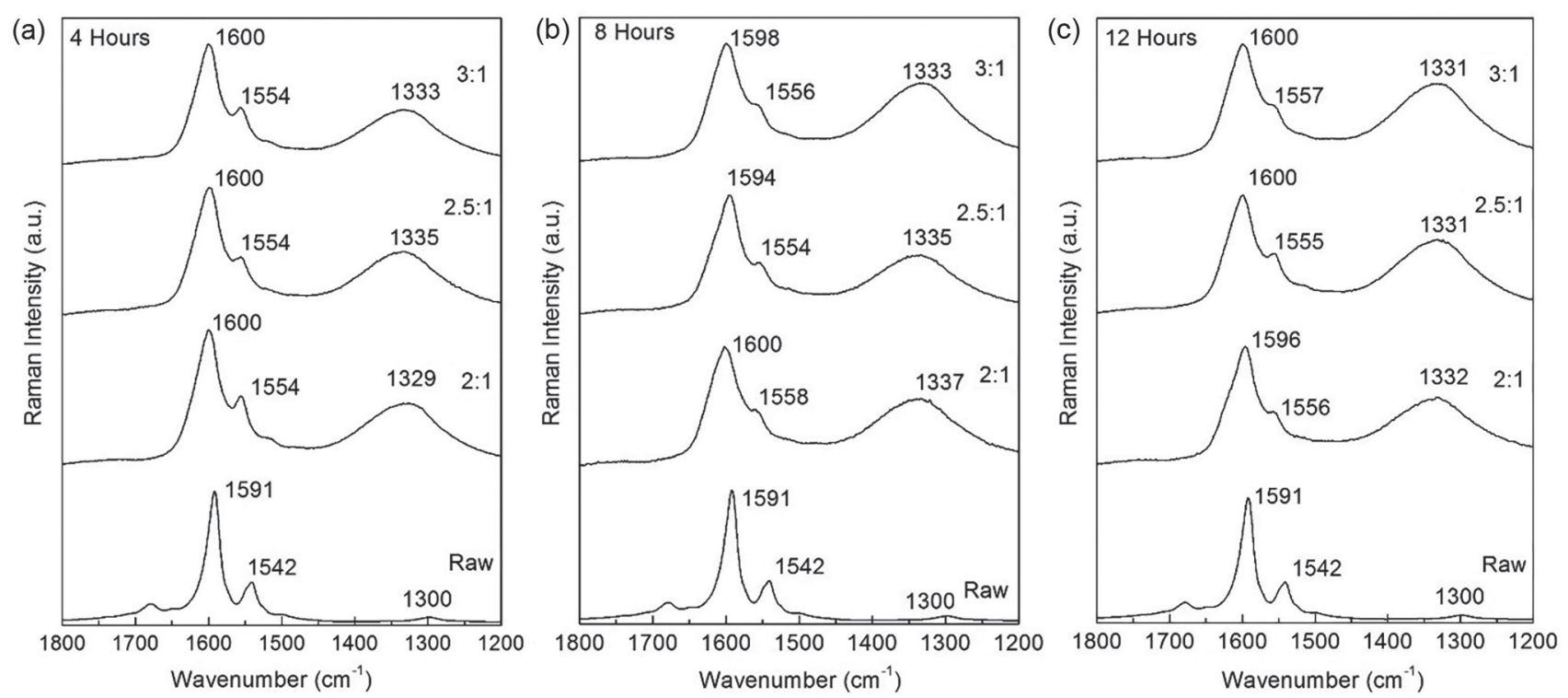

Figure 4. Raman spectra in the $1200-1800 \mathrm{~cm}^{-1}$ range for the products of oxidation reactions at (a) $4 \mathrm{~h}$, (b) $8 \mathrm{~h}$ and (c) $12 \mathrm{~h}$. The D band is assigned at approximately $1300 \mathrm{~cm}^{-1}$ and the $\mathrm{G}^{-}$and $\mathrm{G}^{+}$bands at approximately 1540 and $1590 \mathrm{~cm}^{-1}$, respectively.
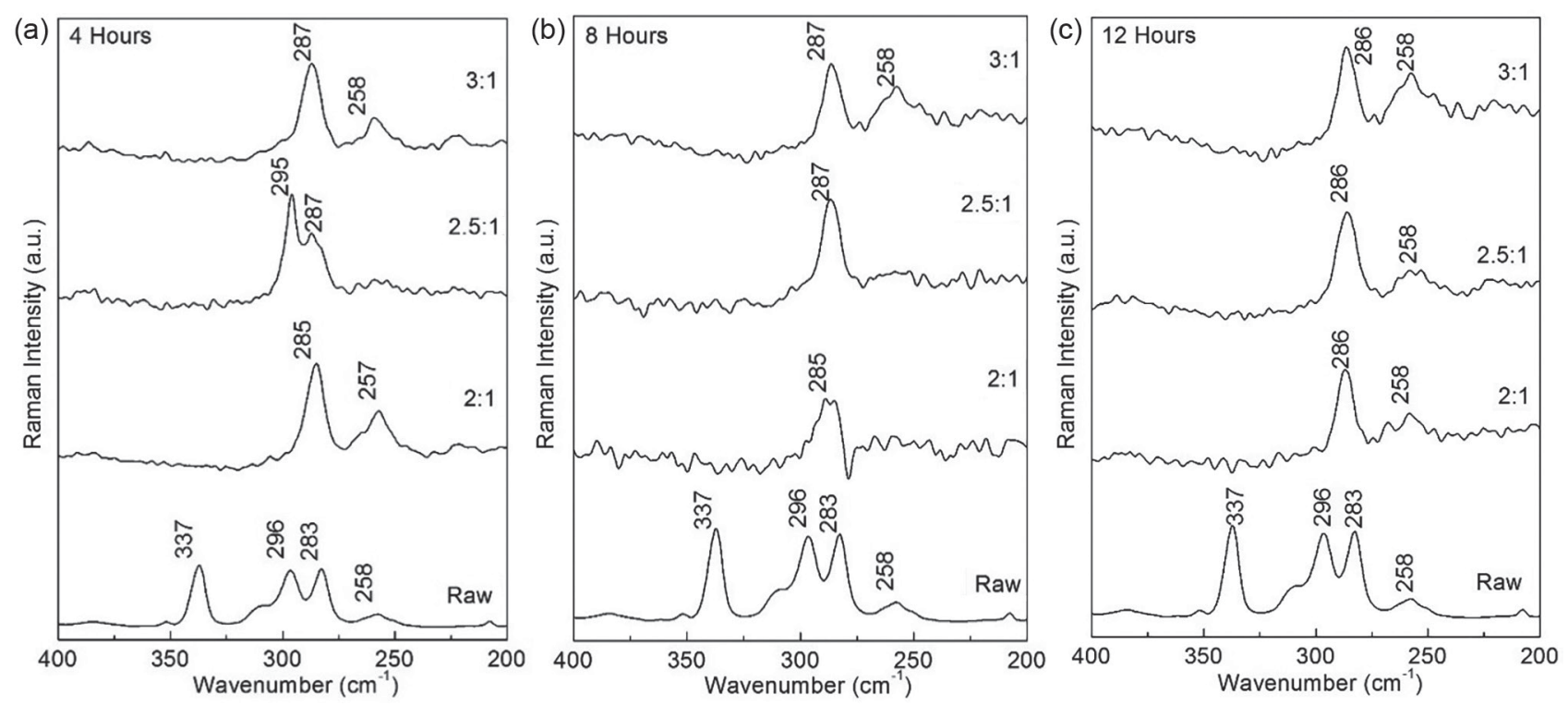

Figure 5. Raman spectra in the range of 200-400 $\mathrm{cm}^{-1}$ for the oxidized samples for (a) $4 \mathrm{~h}$, (b) $8 \mathrm{~h}$ and (c) $12 \mathrm{~h}$ of reaction. The bands are assigned to RBMs. 
frequency approximately $1540 \mathrm{~cm}^{-1}\left(\mathrm{G}^{-}\right)$associated with the vibrations of carbon atoms along the circumferential direction of SWCNT. Both frequencies are sensitive to charge transfer from dopant additions to the tube surface. The $\mathrm{D}$ band is sensitive to the disorder and consequently to the tube surface oxidation. Figure 4 shows an increase of the D band intensity and a shift to higher frequency for all samples, regardless of the reaction time. For the untreated sample, the band was at $1300 \mathrm{~cm}^{-1}$ and shifted to $1330 \mathrm{~cm}^{-1}$ after oxidation, indicating the significant oxidation degree. The $\mathrm{G}^{+}$and $\mathrm{G}^{-}$bands also shift to higher frequency upon oxidation. The $\mathrm{G}^{+}$band shifts from $1591 \mathrm{~cm}^{-1}$ in the untreated sample to $1600 \mathrm{~cm}^{-1}$ in the oxidized samples, whereas the $\mathrm{G}^{-}$band shifts from 1542 to $1554 \mathrm{~cm}^{-1}$ followed by a decrease in intensity and band broadening. The $\mathrm{G}^{+}$band frequency is sensitive to charge transfer from/to the SWCNT. The $\mathrm{G}^{-}$band frequency depends on the electronic nature of the SWCNT (metallic or semiconducting) and also on the SWCNT diameter. ${ }^{22,23}$ The up shifts in the $\mathrm{G}$ bands observed in the Raman spectra upon oxidation can be interpreted as a result of the charge transfer from SWCNT to $\mathrm{NO}_{2}^{+}$and change in the diameter of the SWCNT. ${ }^{16,24}$

The relative $\mathrm{D}$ and $\mathrm{G}$ band intensities $\left(\mathrm{I}_{\mathrm{D}} / \mathrm{I}_{\mathrm{G}}\right)$ provides qualitative information about the structural disorder on the nanotube, i.e., the increase of the oxidation will cause an increase in this ratio. Table 3 shows the $\mathrm{I}_{\mathrm{D}} / \mathrm{I}_{\mathrm{G}}$ ratio for the untreated and oxidized samples. The $\mathrm{I}_{\mathrm{D}} / \mathrm{I}_{\mathrm{G}}$ ratio for the untreated sample was 0.027 ; after $4 \mathrm{~h}$ of reaction, the ratio was 0.37 due to the oxidation of the nanotube surface. The increase of the reaction time to $8 \mathrm{~h}$ promotes an increase in the $\mathrm{I}_{\mathrm{D}} / \mathrm{I}_{\mathrm{G}}$ ratio, suggesting that, after $8 \mathrm{~h}$, the oxidation process reaches a saturation limit where the tube surface is covered by oxygen-containing groups.

Table 3. $I_{D} / I_{G}$ ratio observed for the untreated and oxidized SWCNT samples

\begin{tabular}{lcccc}
\hline Proportion & $\begin{array}{c}{\left[\mathrm{NO}_{2}{ }^{+}\right] /} \\
\left(\mathrm{mol} \mathrm{L}^{-1}\right)\end{array}$ & $4 \mathrm{~h}$ & $8 \mathrm{~h}$ & $12 \mathrm{~h}$ \\
\hline Untreated & 0 & 0.027 & 0.027 & 0.027 \\
$2: 1$ & 1.40 & 0.37 & 0.44 & 0.42 \\
$2.5: 1$ & 1.89 & 0.39 & 0.46 & 0.52 \\
$3: 1$ & 2.56 & 0.37 & 0.59 & 0.54 \\
\hline
\end{tabular}

$I_{D} / I_{G}$ ratio: relative $D$ and $G$ band intensities.

The relationship between the $\mathrm{I}_{\mathrm{D}} / \mathrm{I}_{\mathrm{G}}$, acid proportion and reaction time is shown in Table 3 , with $\mathrm{I}_{\mathrm{D}} / \mathrm{I}_{\mathrm{G}}$ increasing with nitronium ion concentration or reaction time. The higher $\left[\mathrm{NO}_{2}^{+}\right]$and longer reaction time, the larger the $\mathrm{I}_{\mathrm{D}} / \mathrm{I}_{\mathrm{G}}$ ratio, suggesting an increase in the oxidation degree. Moreover, the $I_{D} / I_{G}$ ratio converges for reaction times greater than or equal to $8 \mathrm{~h}$. Thus, the increase of $\left[\mathrm{NO}_{2}^{+}\right]$ and reaction time lead to saturation in the oxidation degree after ca. $8 \mathrm{~h}$. It is also worth noting the small variation of $\mathrm{I}_{\mathrm{D}} / \mathrm{I}_{\mathrm{G}}$ ratio with $\left[\mathrm{NO}_{2}^{+}\right]$for short reaction time $(4 \mathrm{~h})$. It might be interpreted as a rate law proportional to the $\mathrm{NO}_{2}{ }^{+}$concentration, therefore, the variation of $\mathrm{I}_{\mathrm{D}} / \mathrm{I}_{\mathrm{G}}$ with time, which is a parameter for the speed at which products are formed, should increase with $\left[\mathrm{NO}_{2}^{+}\right]$, supporting our hypothesis for controlling the oxidation degree.

Figure 5 shows the $400-200 \mathrm{~cm}^{-1}$ spectral region where the RBM are assigned. The RBM frequency $\left(v_{\mathrm{RBM}}\right)$ is inversely correlated with the SWCNT diameter $\mathrm{d}$ by: $\mathrm{d}=\frac{238 \mathrm{~cm}^{-1} \mathrm{~nm}}{v_{\text {RBM }}} .{ }^{22}$ The band at $337 \mathrm{~cm}^{-1}$ corresponds to a tube diameter of $0.7 \mathrm{~nm}$, as expected for the $(6,5)$ SWCNT. The other bands at 310, 296, 283 and $256 \mathrm{~cm}^{-1}$ in the untreated sample correspond to tubes with diameters of approximately $0.76,0.80,0.82$ and $0.92 \mathrm{~nm}$, respectively. The Raman spectra represented in Figure 5 show a disappearance of the band at $337 \mathrm{~cm}^{-1}$ with the oxidation process, suggesting that tubes with diameter $<0.7 \mathrm{~nm}$ were consumed or had their local diameter increased upon oxidation. In general, the oxidation process promotes an increase in the tube diameter, shifting the $v_{\mathrm{RBM}}$ to smaller values. In Figure 5a, for $4 \mathrm{~h}$ of reaction, the 2.5:1 mixture still has two peaks at 287 and $295 \mathrm{~cm}^{-1}$ with considerable intensity of the bands, suggesting a smaller degree of oxidation. This cannot be explained based on $\mathrm{NO}_{2}{ }^{+}$ concentration and should be due to some oscillation on the reaction conditions, even though the results for $2: 1$ and $3: 1$ are in line with the other reactions at longer time. For the 8 and $12 \mathrm{~h}$ reactions, the Raman spectra show one band at 285 and $258 \mathrm{~cm}^{-1}$, respectively, suggesting that most tubes had an average diameter of ca. $0.83 \mathrm{~nm}$. The oxidation with the $3: 1$ mixture led to an increase of the peak at $258 \mathrm{~cm}^{-1}$, suggesting an enlargement of the nanotubes' local diameter upon oxidation.

Our results of the acid oxidation of SWCNT are in line with those reported by many authors. ${ }^{5,6,23-25}$ Jorio et al. ${ }^{25}$ in his review, reported an increase in the $\mathrm{D}$ band intensity followed by an increase in the $\mathrm{I}_{\mathrm{D}} / \mathrm{I}_{\mathrm{G}}$ ratio upon oxidation. Tchoul et al. ${ }^{6}$ explored the influence of mild nitric acid oxidation on the size and structure of SWCNT following two procedures, one using $8 \mathrm{M}$ of nitric acid with sonication and another with $2.6 \mathrm{M}$ of nitric acid at reflux. The Raman spectra showed an increase in the $\mathrm{I}_{\mathrm{D}} / \mathrm{I}_{\mathrm{G}}$ ratio. In the RBM region, small shifts of the frequencies were observed, along with a decrease of the intensity of the bands at higher frequencies. Gómez et al. ${ }^{7}$ also reported the effects in the structure of the MWCNT by sulfonitric treatment. A solution of $\mathrm{H}_{2} \mathrm{SO}_{4} 98 \%$ and $\mathrm{HNO}_{3} 65 \%(3: 1 \mathrm{v} / \mathrm{v})$ was 
employed for the acid treatment, and the Raman spectra also showed a $\mathrm{D}$ band and $\mathrm{I}_{\mathrm{D}} / \mathrm{I}_{\mathrm{G}}$ ratio increase after the oxidation process. It is also important to mention the effect on the tube length by acid oxidation. It has been well established that the cutting and debundling simultaneously occur in the chemical oxidation of SWCNT. As a consequence, the length and diameter of SWCNT bundles are reduced at the same time. ${ }^{26,27}$ In the present work, the experimental conditions for the oxidation were based on acid mixtures $2: 1,2.5: 1$, and $3: 1(\mathrm{v} / \mathrm{v})$ in a total volume of $50 \mathrm{~mL}$ and the reactions were carried out in an ultrasound bath for $1 \mathrm{~h}$ plus 4,8 or $12 \mathrm{~h}$ with magnetic stirring at room temperature. Therefore, considering the lower temperature and periods of treatment with respect to the previous works, ${ }^{26,27}$ it can be proposed that the length reduction should not be significant to the discussion of the results herein in some extent, for instance for the data related to the $4 \mathrm{~h}$ of treatment. The elimination of smaller diameter tubes was indeed observed by the RBM analysis and the shortening of the nanotubes may be associated with the effects observed in the oxidation at longer periods ( 8 and $12 \mathrm{~h}$ ) and higher concentrations of $\mathrm{NO}_{2}^{+}$.

TGA provides qualitative and quantitative information about nanotube stability. Figure 6 shows the thermograms obtained for the oxidation process after 4,8 and $12 \mathrm{~h}$ for distinct mixtures. Table 4 exhibits the temperature for the greatest rate of mass loss observed in differential TGA (DTGA). The TGA curve for the untreated sample shows the largest rate of mass loss at $474^{\circ} \mathrm{C}$. The oxidation stage is known for its purification effect with the digestion of the metals from the catalysts and the tubes with smaller diameters. This effect led to the increase of the CNT average diameter in the samples, as observed in the Raman spectra analysis. As a result, the temperature of the tube decomposition increases to $>510^{\circ} \mathrm{C}$ for all samples.

The temperatures observed in Table 4 indicate that for all three different oxidation times the increase in acid concentration from 2:1 to 2.5:1 benefited the samples with respect to thermal stability. However, the more concentrated acid treatment seems to damage the nanotubes and lead to decrease in the tendency of thermal stability. Moreover, the TGA shows two other mass loss events at $100{ }^{\circ} \mathrm{C}$ due to moisture release and from $120-400{ }^{\circ} \mathrm{C}$ due to the oxygencontaining groups and residual moisture.

The EDS data were used to analyze the samples before and after the oxidation. The EDS analysis was performed with multiple measurements of different points of the sample and an average of the atomic content provides semiquantitative information about the system composition as the atomic percentage on the sample. Figure 7 shows the oxygen content obtained for samples from distinct
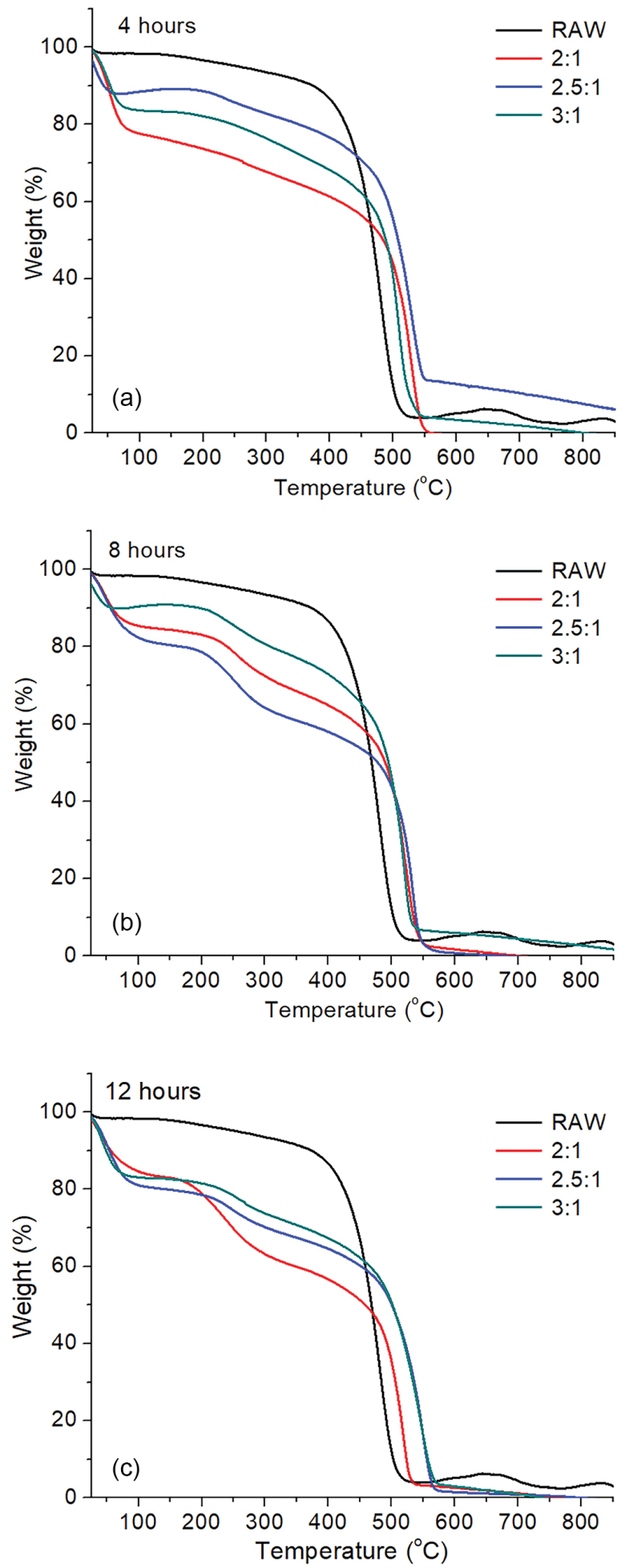

Figure 6. Thermogram of the oxidized samples for (a) 4 h, (b) $8 \mathrm{~h}$ and (c) $12 \mathrm{~h}$ of oxidation.

experiments as function of $\left[\mathrm{NO}_{2}{ }^{+}\right]$and reaction time. For $4 \mathrm{~h}$ reaction the oxygen percentage increases continuously with the $\mathrm{NO}_{2}{ }^{+}$concentration up to $26.2 \%$ (oxidized sample at $3: 1$ acid mixture, $\left.\left[\mathrm{NO}_{2}{ }^{+}\right]=2.56 \mathrm{~mol} \mathrm{~L}^{-1}\right)$. For 8 and $12 \mathrm{~h}$ reactions, the oxidation process reaches saturation quickly 
Table 4. Temperature at the greatest mass loss obtained from DTGA analysis

\begin{tabular}{lcccc}
\hline Proportion & $\begin{array}{c}{\left[\mathrm{NO}_{2}^{+}\right] /} \\
\left(\mathrm{mol} \mathrm{L}^{-1}\right)\end{array}$ & $4 \mathrm{~h}$ & $8 \mathrm{~h}$ & $12 \mathrm{~h}$ \\
\hline Untreated & 0 & 474 & 474 & 474 \\
$2: 1$ & 1.40 & 530 & 525 & 521 \\
$2.5: 1$ & 1.89 & 536 & 534 & 556 \\
$3: 1$ & 2.56 & 510 & 520 & 550 \\
\hline
\end{tabular}

(29.2\% of oxygen), even for the low concentration of $\mathrm{NO}_{2}^{+}$ (1.40 $\left.\mathrm{mol} \mathrm{L}^{-1}\right)$. Therefore, as also suggested by the Raman and TGA analyses, the oxidation process occurs gradually at $4 \mathrm{~h}$ and depends on the $\mathrm{NO}_{2}{ }^{+}$concentration, allowing a fine control of the oxidation degree.

The mass loss in the range of $100-350{ }^{\circ} \mathrm{C}$ also supports the understanding of the oxidation processes. In this temperature range, the loss of oxygen groups occurs. For the process with the $2: 1$ mixture, the mass losses were $13.3,16.9$ and $25.0 \%$ for 4,8 and $12 \mathrm{~h}$, respectively. This increase in the mass loss with time suggests a larger amount of oxygen-containing groups for longer reaction times, in line with the EDS analysis (see Figure 7).

\section{DFT results}

To assist in the characterization of SWCNT oxidized samples, DFT calculations were performed for the molecular models represented in Figure 1. The simulated Raman spectra are shown in Figure 8 for the D and $G$ (Figure $8 \mathrm{a}$ ), and RBM (Figure $8 \mathrm{~b}$ ) regions. For the pristine

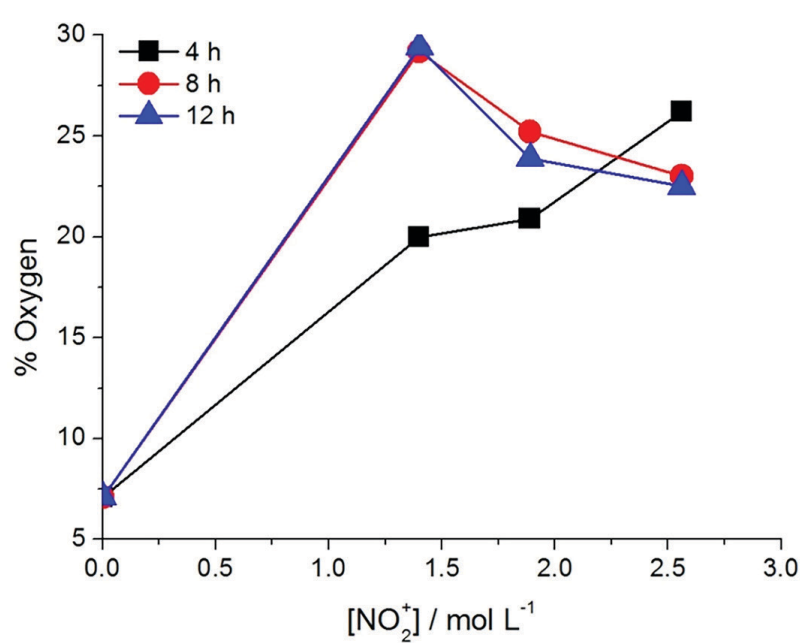

Figure 7. Oxygen percentage obtained by EDS for the products from distinct reactions. Data is average of replicate measurements.

form, all the bands are well defined, as expected for a perfect tube. The insertion of the SW topological defect promotes some changes on the D / G relative intensity, which are intensified in the oxidized structures. As discussed previously, the $\mathrm{I}_{\mathrm{D}} / \mathrm{I}_{\mathrm{G}}$ ratio is used as parameter to monitor the degree of oxidation of the nanotube. This quantity increases with the structural disorder on the tube surface as a consequence of the insertion of oxygen atoms. The calculated $\mathrm{I}_{\mathrm{D}} / \mathrm{I}_{\mathrm{G}}$ ratios are given in Table 5 , showing the lowest $\mathrm{I}_{\mathrm{D}} / \mathrm{I}_{\mathrm{G}}$ ratio for the pristine model $\mathrm{P}$ and an increase with the number of oxygen atoms added to the SWCNT surface. These results closely follow the trend observed experimentally, where the $\mathrm{I}_{\mathrm{D}} / \mathrm{I}_{\mathrm{G}}$ ratio increased from 0.027 to 0.54 upon oxidation (see Table 3 ).
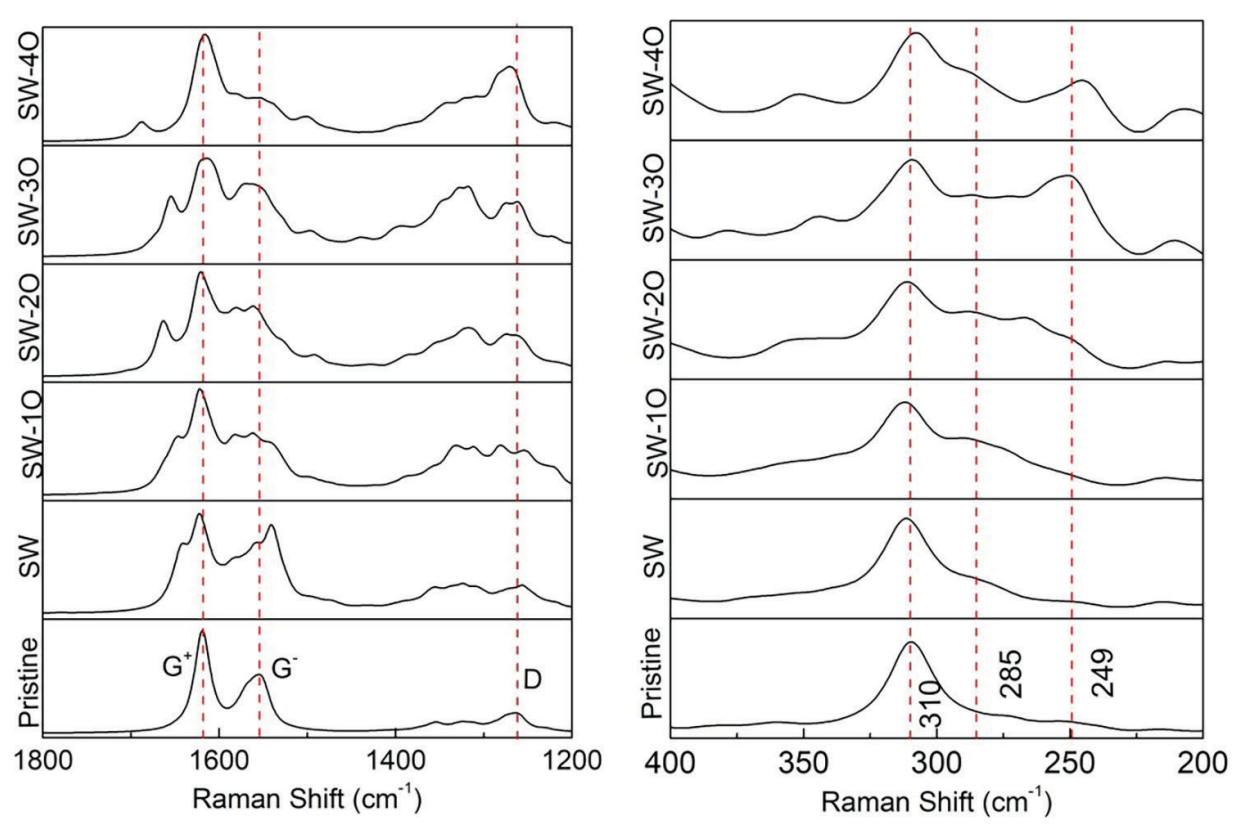

Figure 8. Simulated Raman spectra for the proposed models in the (a) $1800-1200 \mathrm{~cm}^{-1}$ region and (b) RBM region, $400-200 \mathrm{~cm}^{-1}$. 
Table 5. $\mathrm{I}_{\mathrm{D}} / \mathrm{I}_{\mathrm{G}}$ ratio calculated using the simulated Raman spectra, with the $\mathrm{D}$ band at $1270 \mathrm{~cm}^{-1}$ and $\mathrm{G}$ band at $1620 \mathrm{~cm}^{-1}$

\begin{tabular}{lc}
\hline Model & $\mathrm{I}_{\mathrm{D}} / \mathrm{I}_{\mathrm{G}}$ ratio \\
\hline $\mathrm{P}$ & 0.207 \\
$\mathrm{SW}$ & 0.292 \\
$\mathrm{SW}-1 \mathrm{O}$ & 0.478 \\
SW-2O & 0.417 \\
SW-3O & 0.561 \\
SW-4O & 0.700 \\
\hline
\end{tabular}

$\mathrm{I}_{\mathrm{D}} / \mathrm{I}_{\mathrm{G}}$ ratio: relative $\mathrm{D}$ and $\mathrm{G}$ band intensities; $\mathrm{P}$ : pristine single-walled carbon nanotube (SWCNT); SW: an SWCNT with a Stone-Wales (SW) defect; SW-1O, SW-2O, SW-3O and SW-4O: SWCNTs with SW defects oxidized with 1-4 oxygen atoms, respectively.

The low frequency Raman spectra are shown in Figure $8 \mathrm{~b}$. For the $\mathrm{P}$ model, only one signal was predicted at $310 \mathrm{~cm}^{-1}$ due to the RBM vibration. Similar behavior was observed for the SW model, suggesting that small topological defects do not significantly change the tube diameter. The addition of oxygen atoms to the tube surface led to the appearance of bands in the lower frequency region assigned as local-RBMs of the part of surface containing the oxygen atoms.

These results suggest that the addition of oxygen atoms to the SWCNT surface increases the average diameter due to a local distortion in the oxidized region, and, consequently, results in the appearance of new bands at lower frequencies. The simulated Raman spectra aid in the interpretation of the experimental Raman data, in which the disappearance of the signal at $337 \mathrm{~cm}^{-1}$ (Figure 5) and a new band at ca. $287 \mathrm{~cm}^{-1}$ was observed, strongly suggesting an increase in the diameter of the SWCNT after the oxidation.

\section{Conclusions}

In the present study, the acid oxidation of SWCNT was monitored as function of the reaction time and $\mathrm{NO}_{2}{ }^{+}$concentration. The $\left[\mathrm{NO}_{2}{ }^{+}\right]$in the acid mixture was quantified through Raman spectrum analysis with the aid of a calibration plot constructed from a standard solution of $\mathrm{NO}_{2} \mathrm{BF}_{4}$ salts in $\mathrm{H}_{2} \mathrm{SO}_{4}$. The $\left[\mathrm{NO}_{2}{ }^{+}\right]$ranged from 1.40 to $4.48 \mathrm{~mol} \mathrm{~L}^{-1}$ for the $\mathrm{H}_{2} \mathrm{SO}_{4}: \mathrm{HNO}_{3}$ mixtures $2: 1$ and 5:1, respectively. Moreover, for the mixtures $6: 1,7: 1$ and $8: 1$, the concentration of $\mathrm{NO}_{2}{ }^{+}$converged to the limit of $4.33 \mathrm{~mol} \mathrm{~L}-1$. Three $\mathrm{H}_{2} \mathrm{SO}_{4}: \mathrm{HNO}_{3}$ solutions, $2: 1\left(\left[\mathrm{NO}_{2}{ }^{+}\right]=1.40 \mathrm{~mol} \mathrm{~L}-1\right), 2.5: 1\left(\left[\mathrm{NO}_{2}^{+}\right]=1.89 \mathrm{~mol} \mathrm{~L}^{-1}\right)$ and $3: 1\left(\left[\mathrm{NO}_{2}{ }^{+}\right]=2.56 \mathrm{~mol} \mathrm{~L}^{-1}\right)$, were used to oxidize the SWCNTs for 4,8 and $12 \mathrm{~h}$, resulting in nine distinct experiments. After oxidation, the Raman spectra of the resulting samples showed a significant increase of the
D band intensity followed by a shift to higher frequency due to an increase in the structural disorder of the system after oxidation. In the $G$ band region, the decrease of the $\mathrm{G}^{-}$band intensity was followed by a shift to higher frequency. The $\mathrm{G}^{+}$band also shifted to higher frequency, which suggests a significant oxidation degree due to charge transfer between the reactive species. The $\mathrm{I}_{\mathrm{D}} / \mathrm{I}_{\mathrm{G}}$ ratio was analyzed and correlated with the extent of oxidation. The $\mathrm{I}_{\mathrm{D}} / \mathrm{I}_{\mathrm{G}}$ ratio increased with reaction time, converging to an almost constant value after $8 \mathrm{~h}$ of reaction. As expected, the increase of the reaction time and the nitronium ion concentration promoted an increase in the $\mathrm{I}_{\mathrm{D}} / \mathrm{I}_{\mathrm{G}}$ ratio from $0.37\left(\left[\mathrm{NO}_{2}^{+}\right]=1.40 \mathrm{~mol} \mathrm{~L}^{-1}\right.$ and $\left.4 \mathrm{~h}\right)$ to $0.54\left(\left[\mathrm{NO}_{2}{ }^{+}\right]=2.56 \mathrm{~mol} \mathrm{~L}{ }^{-1}\right.$ and $\left.12 \mathrm{~h}\right)$. The RBM analysis confirmed the disappearance of SWCNTs with small diameters and the increase of the average diameter due to the insertion of oxygen-containing groups on the tube surface. The TGA showed an increase in the temperature corresponding to the maximum rate of mass loss from 474 to ca. $550{ }^{\circ} \mathrm{C}$. As observed for the $\mathrm{I}_{\mathrm{D}} / \mathrm{I}_{\mathrm{G}}$ ratio analysis, the increase of the $\mathrm{NO}_{2}{ }^{+}$concentration and reaction time led to an increase in the mass loss between 100 and $350{ }^{\circ} \mathrm{C}$, which was assigned to the number of oxygen-containing groups on the tube walls. From the EDS analysis, we observed a considerable increase of the amount of oxygen-containing groups and found $7.1 \%$ in the pristine form and at least $20 \%$ in the oxidized forms. The percentage of oxygen increased gradually up to $4 \mathrm{~h}$, depending on the $\mathrm{NO}_{2}{ }^{+}$concentration and converged quickly to a limit value of approximately $20 \%$ for reaction times longer than $8 \mathrm{~h}$. The results allow proposing an experimental protocol to get a fine tune of oxidation degree by setting a short reaction time (ca. $4 \mathrm{~h}$ ) and increase smoothly the $\mathrm{NO}_{2}{ }^{+}$concentration (up to ca. $3 \mathrm{~mol} \mathrm{~L}^{-1}$ ). The latter can be accomplished using distinct proportion of $\mathrm{H}_{2} \mathrm{SO}_{4} / \mathrm{HNO}_{3}$ mixture defined by the analytical models constructed in the paper. Moreover, the results reported here contribute to the vast field of the functionalization of SWCNTs, providing chemical insight to controlling acid oxidation.

\section{Acknowledgments}

The authors would like to thank CNPq, FAPEMIG (APQ-00591-15 and APQ-01786-15) and CAPES for providing support to this investigation.

\section{References}

1. Baughman, R. H.; Zakhidov, A.; de Heer, W. A.; Science 2002 , 297, 787.

2. Endo, M.; Hayashi, T.; Kim, Y. A.; Terrones, M.; Dresselhaus, M. S.; Philos. Trans. R. Soc., A 2004, 362, 2223. 
3. De Souza, L. A.; Nogueira, C. A. S.; Ortega, P. F. R.; Lopes, J. F.; Calado, H. D. R.; Lavall, R. L.; Silva, G. G.; Dos Santos, H. F.; De Almeida,W. B.; Inorg. Chim. Acta 2016, 447, 38.

4. Furtado, C. A.; Kim, U. J.; Gutierrez, H. R.; Pan, L.; Dickey, E. C.; Eklund, P. C.; J. Am. Chem. Soc. 2004, 126, 6095.

5. Osorio, A. G.; Silveira, I. C. L.; Bueno, V. L.; Bergmann, C. P.; Appl. Surf. Sci. 2008, 255, 2485.

6. Tchoul, M. N.; Ford, W. T.; Lolli, G.; Resasco, D. E.; Arepalli, S.; Chem. Mater. 2007, 19, 5765.

7. Gómez, S.; Rendtorff, N. M.; Aglietti, E. F.; Sakka, Y.; Suárez, G.; Appl. Surf. Sci. 2016, 379, 264.

8. Hernadi, K.; Siska, A.; Thiên-Nga, L.; Forró, L.; Kiricsi, I.; Solid State Ionics 2001, 141-142, 203.

9. Datsyuk, V.; Kalyva, M.; Papagelis, K.; Parthenios, J.; Tasis, D.; Siokou, A.; Kallitsis, I.; Galiotis, C.; Carbon 2008, 46, 833.

10. Yaya, A.; Ewels, C. P.; Wagner, P.; Suarez-Martinez, I.; Gebramariam Tekley, A.; Rosgaard Jensen, L.; Eur. Phys. J.: Appl. Phys. 2011, 54, 10401.

11. Toebes, M. L.; van Heeswijk, J. M.; Bitter, J. H.; van Dillen, A. J.; de Jong, K. P.; Carbon 2004, 42, 307.

12. Devaux, X.; Vigolo, B.; McRae, E.; Valsaque, F.; Allali, N.; Mamane, V.; Fort, Y.; Soldatov, A. V.; Dossot, M.; Tsareva, S. Y.; ChemPhysChem 2015, 16, 2692.

13. Yang, C.-M.; Park, J. S.; An, K. H.; Lim, S. C.; Seo, K.; Kim, B.; Park, K. A.; Han, S.; Park, C. Y.; Lee, Y. H.; J. Phys. Chem. B 2005, 109, 19242.

14. An, K. H.; Yang, C.-M.; Lee, J. Y.; Lim, S. C.; Kang, C.; Son, J.-H.; Jeong, M. S.; Lee, Y. H.; J. Electron. Mater. 2006, 35, 235.

15. Da Silva Jr., A. M.; Dos Santos. H. F.; Giannozzi, P.; Chem. Phys. Lett. 2013, 582, 123.
16. Porto, A. B.; de Oliveira, L. F. C.; Dos Santos, H. F.; Comput. Theor. Chem. 2016, 1088, 1.

17. Edwards, H. G. M.; Turner, J. M. C.; Fawcett, V.; J. Chem. Soc., Faraday Trans. 1995, 91, 1439.

18. Gong, H.; Kim, S.-T.; Lee, J. D.; Yim, S.; Appl. Surf. Sci. 2013, 266, 219.

19. Becke, A. D.; J. Chem. Phys. 1993, 98, 5648.

20. Petersson, G. A.; Bennett, A.; Tensfeldt, T. G.; Al-Laham, M. A.; Shirley, W. A.; J. Chem. Phys. 1988, 89, 2193.

21. Petersson, G. A.; Al-Laham, M. A.; J. Chem. Phys. 1991, 94, 6081.

22. Dresselhaus, M. S.; Dresselhaus, G.; Jorio, A.; Souza Filho, A. G.; Saito, R.; Carbon 2002, 40, 2043.

23. Dresselhaus, M. S.; Dresselhaus, G.; Saito, R.; Jorio, A.; Phys. Rep. 2005, 406, 47.

24. An, K. H.; Park, J. S.; Yang, C.-M.; Jeong, S. Y.; Lim, S. C.; Kang, C.; Son, J.-H.; Jeong, M. S.; Lee, Y. H.; J. Am. Chem. Soc. 2005, 127, 5196.

25. Jorio, A.; Santos, A. P.; Ribeiro, H. B.; Fantini, C.; Souza, M.; Vieira, J. P. M.; Furtado, C. A.; Jiang, J.; Saito, R.; Balzano, L.; Resasco, D. E.; Pimenta, M. A.; Phys. Rev. B 2005, 72, 075207.

26. Liu, J.; Rinzler, A. G.; Dai, H.; Hafner, J. H.; Bradley, R. K.; Boul, P. J.; Lu, A.; Iverson, T.; Shelimov, K.; Huffman, C. B.; Rodriguez-Macias, F.; Shon, Y.-S.; Lee, T. R.; Colbert, D. T.; Smalley, R. E.; Science 1998, 280, 1253.

27. Zhang, J.; Zou, H.; Qing, Q.; Yang, Y.; Li, Q.; Liu, Z.; Guo, X.; Du, Z.; J. Phys. Chem. B 2003, 107, 3712.

Submitted: March 7, 2018

Published online: June 18, 2018 